\title{
British MRC reprimanded over clinical test record
}

There was both good and bad news last month for Britain's Medical Research Council (MRC) over its past handling of the question of how much information researchers should provide to patients and physicians involved in clinical experiments.

A panel of inquiry cleared MRC-funded researchers of any significant misconduct over a range of studies that had been carried out in the 1950 s and 1960 s involving the impact of radiation on human subjects. But it accepted that more could have been done to tell those involved about the nature of the experiments.

There was harsher judgement over charges that the MRC and the Department of Health failed to pass on warnings in the late 1970s about the possible dangers of Creutzfeldt-Jakob disease (CJD) arising from the use of human growth hormone extracted from human pituitary glands. The relatives of eight patients who were being treated with the hormone at the time, and who subsequently died from CJD, have won the right to compensation from the government.

The CJD ruling was handed down by an appeals court in London. It follows an earlier judgement that the MRC-which was producing the hormone to treat patients under a program started in 1957had been negligent in not passing on warnings originating in the US about the possible risk of infection (Nature 380; $661,1996)$. Last month's verdict was based on statements by the clinicians responsible for treating the deceased individuals, who said that if they had been told of the warnings, they would have halted therapy.

So far, MRC officials have declined on legal advice to comment on the CJD verdicts. But council officials admit that the implications of the affair-which is unrelated to current scares over bovine spongiform encephalitis-were a major influence on discussions that led to the publication of 'pilot' guidelines on good clinical practice earlier this year.

The guidelines, intended "to ensure that focus [of the supervision of clinical trials] is on the quality of the study and the interest of patients," also took into account an ethical analysis of the 1950s and 1960s radiation experiments. Some of these studies involved tracing the changing function of the thyroid gland during pregnancy. Others entailed feeding chapatis (unleav-

ened bread) laced with radioactive iron to Punjabi women living in the city of Coventry as part of a nutrition-based study into ways of combating iron deficiency.

Following a 1995 broadcast of a highly critical television documentary on the conduct of the experiments, the MRC rejected demands to set up a major investigation into the experiments along the lines of that ordered by President Bill Clinton in 1994 over similar trials in the US (Nature Med. 1; $1112,1995)$. But it did agree to set up an inquiry into the way that the experiments were conducted.

In its report, the British radiation inquiry committee concludes that the risk in-

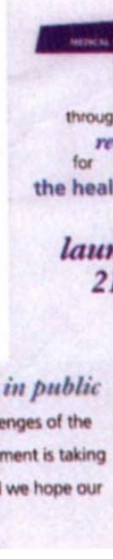

The rulings coincided with the release of an MRC booklet promoting the Council's work in public health research.

volved in the studies "was very small, or negligible" and that there is no evidence that any of the participants have been physically harmed. It also says that, despite one instance-the refusal to return the bodies of dead children whose bones had been removed for radiation testing to their parents-in which the conduct of some of those working on the study was 'clearly unacceptable,' all of the tests involved 'met the research standards prevalent at the time.'

But the five-member committee did conclude that some of the participants had been caused long-term worry and distress, which "could have been avoided by better communication by researchers during the studies, and by ensuring information on the study was readily available afterwards."

MRC officials say that most of the recommendations made by the committee--such as the call for records of participation in research to be included in patient records held by a gen-

MRC eral practitioner-are addressed in the new guidelines, although these await further refinement after discussion with researchers and other researchfunding organizations.

"There is still more we can do now to improve the information and advice available to patents and volunteers participating in research, and to ensure that their consent is truly informed," says Rabbi Julia Neuberger, chief executive of the King's Fund in London, who chaired the committee.

DAVID DICKSON, LONDON

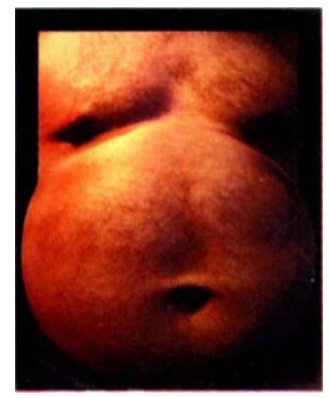

NIH increase efforts to tackle obesity

The National Institutes of Health (NIH) have launched two new initiatives to battle obesity. Last month it announced a new research effort aimed at a more comprehensive understanding of the science underlying a disease now recognized as a major public health problem not only in the US but worldwide. And on June 17 th, a 300 page document released by the National Heart, Lung and Blood Institute (NHLBI) and the National Institute of Diabetes, Digestive and Kidney Diseases (NIDDK), became the first Federal guidelines to instruct physicians in the identification, evaluation, and treatment of overweight and obese adults.

"The biology of weight regulation has now become an accepted field of research, with the identity of molecular, genetic and behavioral elements that all contribute to the disease," says Robert Eckel, professor of medicine at the University of Colorado and an extramural member of a group that met with NIH director Harold Varmus to request increased funding for obesity research.

The group (comprising six intramural and twelve extramural program directors), called for extra funding on four fronts: to 